\title{
Axonal Signals Regulate the Differentiation of Non-Myelin-Forming Schwann Cells: An Immunohistochemical Study of Galactocerebroside in Transected and Regenerating Nerves
}

\author{
Kristján R. Jessen, Rhona Mirsky, and Louise Morgan \\ Department of Anatomy and Embryology, University College London, London WC1E 6BT, UK
}

Little is known about the factors involved in directing and maintaining the divergent differentiation of the 2 major Schwann cell variants, myelin and non-myelin-forming cells, in peripheral nerves. There is strong evidence that the differentiation of myelin-forming cells depends critically on cellcell signaling through contact with appropriate axons. In this paper we ask whether this remarkable dependence of the Schwann cell on axonal contact for full differentiation is unique to those cells that form myelin or whether axonal signaling is also an important factor in the differentiation of non-myelin-forming Schwann cells.

Sciatic nerves or cervical sympathetic trunks of adult rats were either transected or crushed and the axons allowed to degenerate and, in the case of crushed nerves, to regenerate into the distal stump for periods of time varying from $2 \mathrm{~d}$ to 9 weeks. The distal stump of the nerve was excised at specific times, the Schwann cells dissociated and immunolabeled with antibodies to galactocerebroside. In the sciatic nerve, which contains a mixture of non-myelin-forming and myelin-forming Schwann cells, transection resulted in a loss of galactocerebroside expression from the surface of all the Schwann cells in the distal stump over a 9 week period, irrespective of their original phenotype. In crushed sciatic nerves, where axons were allowed to regrow into the distal stumps, the number of Schwann cells expressing immunohistochemically detectable quantities of galactocerebroside in the stump declined over the first 3 weeks, but by 9 weeks after crush the total percentage of galactocerebroside-positive cells in the nerve had risen to control levels. To study non-myelin-forming Schwann cells specifically, we used the cervical sympathetic trunk, in which more than $99 \%$ of the Schwann cells are non-myelin-forming cells. In this nerve, after transection or crush, the percentage of galactocerebroside-positive Schwann cells in the distal stump declined to a basal level by 6-7 $d$ after injury and was fully restored 8 weeks after injury in crushed nerves. These results were confirmed using antibodies to galactocerebroside and neu-

\footnotetext{
Received Dec. 29, 1986; revised Mar. 18, 1987; accepted Apr. 1, 1987.

This research is supported by the Medical Research Council of Great Britain, Action Research for the Crippled Child, and the Multiple Sclerosis Society of Great Britain. Antibodies were kindly donated by Drs. B. Ranscht, J. Wood, B. Anderton, and J. P. Brockes.

Correspondence should be addressed to Kristján R. Jessen, Department of Anatomy and Embryology, University College London, Gower Street, London WC1E 6BT, UK.

Abbreviations: $\mathrm{G}$ anti-RIg-Fl, goat anti-rabbit Ig fluorescein; G anti-MIg-Rd, goat anti-mouse Ig rhodamine; GC, galactocerebroside.

Copyright (C) 1987 Society for Neuroscience $0270-6474 / 87 / 103362-08 \$ 02.00 / 0$
}

rofilament and immunofluorescence to label frozen sections of control, cut, or crushed nerves. In parallel experiments in vitro, Schwann cells from the cervical sympathetic trunk failed to maintain galactocerebroside expression on poly-L-lysine, laminin, collagen, or extracellular matrix. Thus extracellular matrix components do not appear to affect galactocerebroside expression in Schwann cells.

The results demonstrate that cell-cell signaling from axon to Schwann cell is important not only in myelin formation, but also in the differentiation of the Schwann cells of unmyelinated fibers.

Little is known about the factors that are involved in directing and maintaining the divergent differentiation of Schwann cells in peripheral nerves. This process results either in the formation of Remak fibers, an arrangement in which Schwann cells do not form myelin but, instead, accommodate axons in grooves or deep invaginations that run along their surface, or in the formation of myelin sheaths by Schwann cells around the largerdiameter axons. There is strong evidence that differentiation of the myelin-forming Schwann cells, i.e., synthesis of the myelin membrane, depends on cell-cell signaling through contact with appropriate axons. In particular, in vivo experiments (Aguayo et al., 1976; Weinberg and Spencer, 1976) show that axonal signals determine whether Schwann cells in a mature nerve will make myelin or not, while tissue culture studies suggest that azonal contact is necesary not only to trigger formation of the myelin sheath but also to maintain the expression of high levels of several of the myelin component molecules, such as galactocerebroside (GC), basic protein, $P_{0}$, and $P_{2}$ (Mirsky et al., 1980; Winter et al., 1982; Poduslo et al., 1985).

$\mathrm{GC}$ is a glycolipid that is a major component of the myelin sheath, but it is also, as we have recently shown, a ubiquitous component of the plasma membrane of non-myelin-forming Schwann cells in unmyelinated fibers (Jessen et al., 1985). In the differentiation of myelin-forming Schwann cells, GC can be detected at the onset of myelin synthesis just prior to the appearance of the myelin-specific proteins and long before the attainment of terminal morphological differentiation (Ranscht et al., 1982; Winter et al., 1982). In non-myelin-forming Schwann cells, GC appears nearer the time at which final morphological differentiation is achieved, at about the same time or soon after individual axons segregate into separate troughs in the Schwann cell cytoplasm (Jessen et al., 1985).

In this paper we ask whether the remarkable dependence of the Schwann cell on axonal contact for full differentiation is unique to those cells that form myelin, or whether this intriguing 
relationship between axons and Schwann cells also exists in the differentiation of non-myelin-forming cells, which comprise a major population of Schwann cells in peripheral nerves. That the latter might be the case has been suggested by the observation that GC expression declines in non-myelin-forming Schwann cells when they are removed from developing rats and maintained in dissociated cell culture on poly-L-lysine-coated surfaces (Jessen et al., 1985). We have now addressed this issue by studying the effects of nerve transection, nerve crush, and nerve regeneration on the expression of GC in myelin- and non-myelin-forming Schwann cells in situ in adult rats. The effect of several extracellular matrix components-including collagen, laminin, and extracellular matrix from bovine endothelial cellson the rate of disappearance of GC from Schwann cells in dissociatcd ccll culturc has also bcen cxamincd to detcrmine whether these components affect GC expression.

Our results show that axonal contact is crucial for the maintenance of GC in both myelin-and non-myelin-forming Schwann cells in situ. Thus, axonal signals play a part in controlling the plasma membrane composition not only of myelin-forming but of non-myelin-forming Schwann cells.

\section{Materials and Methods}

\section{Denervation}

Adult Sprague-Dawley rats, weighing 90-110 gm, were anesthetized and the left sciatic nerve either cut or crushed $2-4 \mathrm{~mm}$ below the sciatic notch for $8 \mathrm{~min}$ using artery clips. In other experiments, the left cervical sympathetic trunk was either cut and the proximal stump rerouted into the sternomastoid muscle, or crushed 5-7 mm below the superior cervical ganglion. The site of the crush was marked with carbon powder. After surgery, rats were kept for periods of time ranging from $4 \mathrm{~d}$ to 2 months before the nerves were removed for dissociation and analysis. The distal stump of the cut or crushed nerve was measured and an equivalent length of the unoperated nerve on the right side was used as a control

\section{Cell dissociation and culture}

Cervical sympathetic trunks were removed from adult Sprague-Dawley rats of various ages, ranging from $30 \mathrm{~d}$ to 2 months old. The nerves were desheathed and then placed in $150 \mu \mathrm{l}$ of $0.2 \%$ collagenase (Cooper Biomedical, Cochranville, PA) plus $0.125 \%$ trypsin (Gibco, Grand Island, NY) in $\mathrm{Ca}^{2+}, \mathrm{Mg}^{2+}$-free Dulbecco's modified Eagle's medium (DMEM). The tissue was then chopped and placed in an incubator gassed with $5 \% \mathrm{CO}_{2}$ at $37^{\circ} \mathrm{C}$ for $30 \mathrm{~min}$. The medium was drained off, replaced, and the incubation repeated twice more. Then an equal volume of minimal Eagle's medium with 0.02 м HEPES buffer (MEM-H), pH 7.2 , plus $10 \%$ fetal calf serum (FCS) were added to the medium and, using a $1 \mathrm{ml}$ syringe, the nerves were dissociated by passing them 2-3 times through a 25 -gauge needle. The suspension was centrifuged for $10 \mathrm{~min}$ at $500 \times \mathrm{g}$. The supernatant was drained off and the cells treated in one of 3 ways. Cells that were to be immunolabeled immediately after the dissociation were either resuspended in $40 \mu \mathrm{l}$ of MEM-H and cytocentrifuged or dried directly onto a poly-L-lysine-coated microscope slide. Cytospun cells were immediately fixed in $2 \%$ formaldehyde in PBS for $5 \mathrm{~min}$, washed in PBS, and then labeled with antibodies. Cells dried overnight were rehydrated in 4\% formaldehyde in PBS for $5 \mathrm{~min}$, washed thoroughly in PBS, and labeled with antibodies. Cells that were to be maintained in culture were resuspended in DMEM plus $10 \%$ FCS or calf serum, plated out in 24-well trays onto $13 \mathrm{~mm}$ glass coverslips coated with different substrates (see below) at a density of $5-10,000$ cells/well, and maintained in a $5 \% \mathrm{CO}_{2}$-gassed incubator at $37^{\circ} \mathrm{C}$.

\section{Frozen sections}

In some experiments the cut or crushed nerve and the unoperated control were removed and mounted directly in liver using OCT compound (Miles Scientific, Napierville, IL) before being frozen in isopentane cooled in liquid $\mathrm{N}_{2}$. In other experiments the nerves were prefixed in $0.67 \%$ $\mathrm{OsO}_{4}, 0.83 \%$ glutaraldehyde in sodium cacodylate buffer, $\mathrm{pH} 7.2$ (Hirsch and Fedorko, 1968), for $1 \mathrm{hr}$ at $4^{\circ} \mathrm{C}$. They were washed thoroughly in
PBS and kept overnight in 30\% sucrose in PBS before mounting and freezing. Frozen sections, 3-5 $\mu \mathrm{m}$, were cut on a Bright cryostat and dried on gelatin-coated microscope slides prior to immunolabeling.

\section{Antibodies}

Ascites fluid containing mouse monoclonal antibody to GC was produced and characterized by Ranscht et al. (1982). It is of the IgG3 subclass and was routinely used at a dilution of 1:200, although clear visualization of GC on the cytocentrifuged cells could be obtained at dilutions as low as 1:1000. Rabbit antiserum to bovine S-100 protein (DAKO Immunoglobulins, Copenhagen, Denmark) was used at a dilution of 1:100 in cytocentrifuged and dricd preparations, and at 1:200 on cells in dissociated cultures. Rabbit antiserum to $P_{0}$ was produced and characterized by Dr. J. P. Brockes and used as described previously (Jessen et al., 1985). Ascites fluid containing mouse monoclonal antibody to neurofilament was produced and characterized by Wood and Anderton (1981) and used at a dilution of 1:200 in combination with supernatants from 3 other monoclonal antibodies (BF10 B7; RS18; $147 \mathrm{D} 11$ ) to neurofilament proteins produced and characterized by Anderton et al. (1984). The supernatants were all diluted 1:3. Tetramethyl rhodamine conjugated to goat anti-mouse Ig ( $\mathrm{G}$ anti-MIg-Rd) (Cappel Laboratories, Cochranville, PA), adsorbed with rabbit Ig to remove cross-reacting antibodies, was used at a dilution of 1:100. Fluorescein conjugated to goat anti-rabbit Ig (G anti-RIg-Fl) (Nordic Laboratories, Maidenhead, UK), adsorbed with mouse Ig to remove cross-reacting antibodies, was used at a dilution of 1:100. Biotinylated donkcy antirabbit Ig and streptavidin-fluorescein (Amersham International, Amersham, UK) were used at a dilution of 1:100. Antibodies were diluted in PBS containing $0.1 \mathrm{M}$ lysine and $10 \% \mathrm{FCS}$ or, in the case of unfixed dissociated cell cultures, in MEM-H plus $10 \%$ FCS. Control antibodies-normal mouse ascites (1:100 or 1:200) in the case of GC and neurofilament antibodies, and normal rabbit serum for the S-100-were used at the appropriate dilution.

\section{Immunofluorescence}

Cytocentrifuged or air-dried cells. After fixation in formaldehyde, cells were incubated with antibodies to GC for $1 \mathrm{hr}$ (cytocentrifuged cells) or for $2^{1 / 2} \mathrm{hr}$ (air-dried cells) at room temperature. They were washed 3 times in PBS and then incubated with G anti-MIg-Rd for $30 \mathrm{~min}$ After washing, cells were fixed in 4\% paraformaldehyde in PBS for 20 min, followed by $10 \mathrm{~min}$ in $95 \%$ ethanol $/ 5 \%$ acetic acid at $-12^{\circ} \mathrm{C}$. Cells werc washed thoroughly in PBS and then incubated with antibodies to S-100 or $\mathbf{P}_{0}$ for $30 \mathrm{~min}$ (cytocentrifuged cells) or for $3 \frac{1}{2} \mathrm{hr}$ (air-dried cells), followed by $\mathrm{G}$ anti-RIg-Fl or biotinylated donkey anti-rabbit $\mathrm{Ig}$ and streptavidin-fluorescein. After washing, cells were mounted in Citifluor (Chemistry Department, City University, London) to prevent fading.

Dissociated cell cultures and frozen sections. Single- and double-label immunofluorescence experiments using antibodies to GC neurofilament and S-100 were performed as described previously (Mirsky and Jessen. 1984).

\section{Effects of substrate composition on $G C$ expression by Schwann cells}

Thirteen millimeter glass coverslips were incubated with poly-L-lysine $(1 \mathrm{mg} / \mathrm{ml})$ (Sigma) at room temperature for $24 \mathrm{hr}$, washed with 4 changes of distilled water over a period of $4 \mathrm{~d}$, and allowed to dry.

In some experiments, these coverslips were incubated with $50 \mu \mathrm{l}$ of purified laminin $(20 \mu \mathrm{g} / \mathrm{ml})$ in $0.1 \mathrm{~m}$ borate buffer, $\mathrm{pH} 8.6$, for $30 \mathrm{~min}$, washed with 5 changes of MEM-H, and then either stored overnight at $4^{\circ} \mathrm{C}$ or washed in DMEM plus $10 \%$ FCS and used immediately. In other experiments, bovine corneal endothelial cells obtained from Dr. J. P. Brockes, were plated out in 24-well plates onto the poly-L-lysine-coated coverslips in DMEM plus $10 \%$ calf serum, $5 \%$ FCS. Cells were placed in a $5 \% \mathrm{CO}_{2}$-gassed incubator at $37^{\circ} \mathrm{C}$ and allowed to reach confluence. They were then switched to the same medium containing $3 \%$ dextran T40 for $3 \mathrm{~d}$. Afterwards, they were washed 3 times with PBS and placed in $20 \mathrm{mM} \mathrm{NH}_{4} \mathrm{OH}$ for 10-20 min, during which time cell lysis occurred. The extracellular matrix produced by the cells, which still adhered to the coverslips, was washed 6 times with PBS, and coverslips were stored in PBS containing antibiotics at $4^{\circ} \mathrm{C}$ until required.

To test the effects in vitro of different substrates on GC disappearance from non-myelin-forming Schwann cells, dissociated cell cultures from 


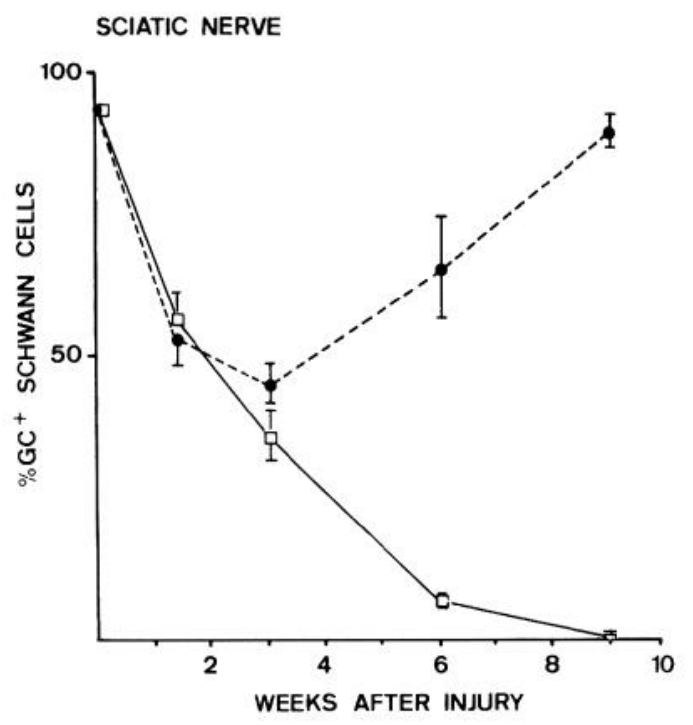

Figure 1. Disappearance and reappearance of GC in S-100-positive Schwann cells in the distal stump of cut (squares) and crushed (circles) sciatic nerves. At specified periods after cut or crush, the distal stump of the sciatic nerve was excised, dissociated enzymatically, and the cells labeled with antibodies to S-100 and GC, as described in Materials and Methods. In the cut nerve, GC disappears from all the Schwann cells in the distal stump over a period of 9 weeks. In contrast, in the crushed nerve GC disappears from some Schwann cells over the first 3 weeks, but thereafter the percentage of GC-positive Schwann cells starts to rise, until by 9 weeks after crush, almost all the Schwann cells in the distal stump are again GC-positive, the number being indistinguishable from that in control, unoperated nerves. Results at each time point were obtained from a minimum of 3 experiments, with a total of at least 900 Schwann cells counted.

cervical sympathetic trunks of $100 \mathrm{gm}$ adult Sprague-Dawley rats were prepared as described above. Cells were plated out at 5000 cells $/ 13 \mathrm{~mm}$ coverslip on either poly-L-lysine, poly-L-lysine plus laminin, poly-Llysine plus rat tail collagen, or poly-L-lysine plus extracellular matrix, in DMEM plus $10 \%$ calf serum or FCS. The percentage of GC-positive Schwann cells in each type of culture was measured at $24 \mathrm{hr}$ intervals over the next $4 \mathrm{~d}$, using double-label immunofluorescence with antibodies to GC and S-100 protein, which is specific for Schwann cells in these cultures (Brockes et al., 1979; Mirsky and Jessen, 1984).

\section{Results}

\section{Effects of nerve transection or crush on GC expression in situ in sciatic nerve}

It can be estimated that the rat sciatic nerve contains about 23 non-myelin-forming Schwann cells for every myelin-forming cell (Friede and Samorajski, 1968; Webster, 1971; Peyronnard et al., 1973; Schlaepfer and Myers, 1973). Therefore, enzymatic dissociation of excised sciatic nerves yields a mixture of the 2 Schwann cell variants. In rats $35 \mathrm{~d}$ of age or older, both types of Schwann cell express GC in situ (Jessen et al., 1985). At intervals from $10 \mathrm{~d}$ to 9 weeks following nerve transection or crush, the distal stump of the left sciatic nerve was excised, and the Schwann cells enzymatically dissociated, air-dried onto microscope slides, and immediately labeled with antibodies to GC and S-100, used in this system as a Schwann cell marker (Brockes et al., 1979; Mirsky and Jessen, 1984), in order to monitor directly the decline in the number of GC-positive Schwann cells in the distal stump (Fig. 1).

Ten days after transection of the sciatic nerve, the number of GC-positive Schwann cells in the distal stump had dropped from $93.9 \pm 0.80 \%$, seen in control nerves, to $56.9 \pm 5.09 \%$. After
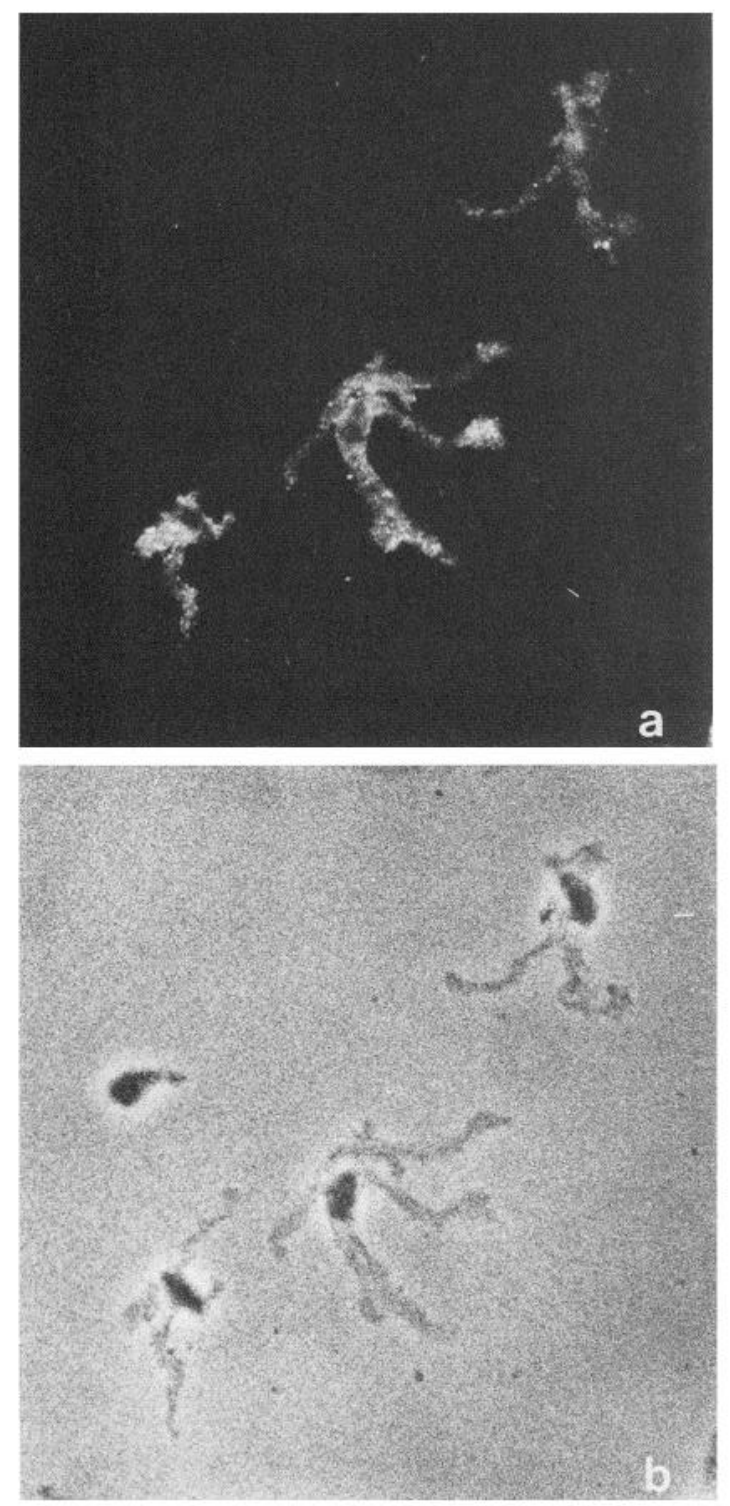

Figure 2. Cell surface GC immunofluorescence in non-myelin-forming Schwann cells, freshly isolated from a sciatic nerve which has been allowed to regenerate for 9 weeks following nerve crush. Note that the 3 GC positive cells $(a)$ carry short processes which can also be seen with phase contrast $(b) .(\times 600$.

3 weeks, $30.7 \pm 4.43 \%$ of Schwann cells were still GC-positive, while at 6 weeks following denervation, GC-positive cells comprised $7.6 \pm 1.25 \%$, and at 9 weeks $1.6 \pm 0.23 \%$ of the total Schwann cells counted (Fig. 1). Undigested myelin segments, often seen in the preparations from normal nerves, became progressively fewer and were not seen at 6 and 9 weeks. Since the major peripheral myelin glycoprotein $P_{0}$ is expressed by myelinforming but not by non-myelin-forming Schwann cells, some slides at each time point were double-labeled with antibodies to $\mathrm{GC}$ and $\mathrm{P}_{0}$, so that we could monitor separately the GCpositive cells that were also $\mathrm{P}_{0}$-positive and therefore represented Schwann cells that had been making myelin before transection. At 3 and 6 weeks following transection or crush, many of the S-100-positive cells were grossly swollen and appeared to be loaded with myelin debris. While cells of this appearance always labeled with antibodies to both $\mathrm{GC}$ and $\mathrm{P}_{0}$, no GC- 


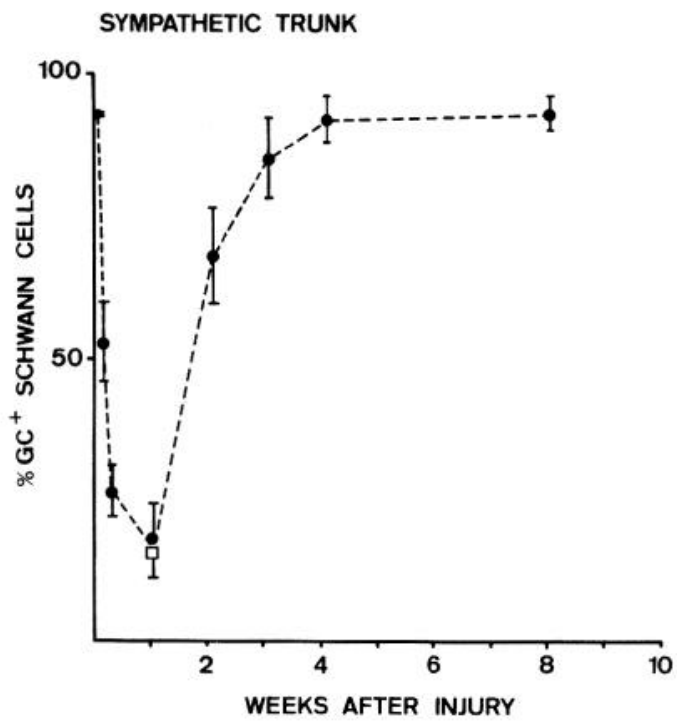

Figure 3. Disappearance and reappearance of GC in S-100-positive Schwann cells in the distal stump of crushed (circles) and cut (squares) cervical sympathetic trunks. At specified points after crush or cut, the distal stump of the cervical sympathetic trunk was excised, dissociated, and the cells labeled with antibodies to S-100 and GC, as described in Materials and Methods. In the crushed nerve, GC disappears rapidly from the Schwann cells over the first $7 \mathrm{~d}$, and thereafter the proportion of GC-positive Schwann cells starts to increase again. By 4 weeks after crush, the percentage of GC-positive Schwann cells in the distal stump has returned to control levels. The rate of disappearance of $\mathrm{GC}$ is similar in the distal stump of the cut nerve, reaching a basal level at 6-7 d after cut. Results at each time point were obtained from a minimum of 3 experiments, with a total of at least 900 Schwann cells counted.

positive cells with the characteristic morphology of non-myelinforming cells (see below) were found at 3 weeks or later. This suggests that GC disappears more slowly from the myelin-forming cells than from the non-myelin-forming ones. At 9 weeks following transection, no $\mathrm{P}_{0}$-positive cells were seen.
In the crushed sciatic nerve, where axons were allowed to regrow into the nerve after injury (Fig. 1), a similar slow initial decline in the number of GC-positive Schwann cells in the distal portion of the nerve was seen, so that only $45.9 \pm 3.56 \%$ of the Schwann cells were GC-positive at 3 weeks after crush. Thereafter, as regeneration proceeded and new axons grew into the stump, the number of GC-positive Schwann cells increased, reaching $66.1 \pm 9.25 \%$ at 6 weeks. By 9 weeks many undigested myelin segments, similar to those seen in preparations from unoperated normal nerves, were again visible. They were positively labeled with antibodies to both $\mathrm{GC}$ and $\mathrm{P}_{0}$. The single Schwann cells in these preparations were of 2 types: S-100positive, $\mathrm{P}_{0}$-negative cells commonly carrying short, feathery processes and expressing cell-surface GC immunoreactivity, i.e., non-myelin-forming Schwann cells similar to those seen in preparations from unoperated control nerves (Fig. 2), and S-100, $\mathrm{P}_{0}$ positive cells of irregular, rounded appearance, which also expressed GC, i.e., myelin-forming cells. The total proportion of GC-positive Schwann cells in these preparations was $90.8 \pm$ $3.01 \%$.

\section{Effects of nerve crush or transection on $G C$ expression in situ in the cervical sympathetic trunk}

The experiments on the sciatic nerve suggested that in situ GC disappeared more rapidly from denervated non-myelin-forming cells than from denervated myelin-forming cells. To observe directly the time course of GC disappearance and re-expression in non-myelin-forming Schwann cells in situ, we turned to a nerve that contains a near-homogeneous population of nonmyelin-forming cells, the rat cervical sympathetic trunk. In this nerve, more than $99 \%$ of axons are unmyelinated (Aguayo et al., 1972; Dyck and Hopkins, 1972), and it can be estimated that approximately the same proportion of the total Schwann cell population in the nerve consists of non-myelin-forming cells (Webster, 1971; Peyronnard et al., 1973; Schlaepfer and Myers, 1973). More than $90 \%$ of these non-myelin-forming Schwann cells express immunohistochemically detectable amounts of GC
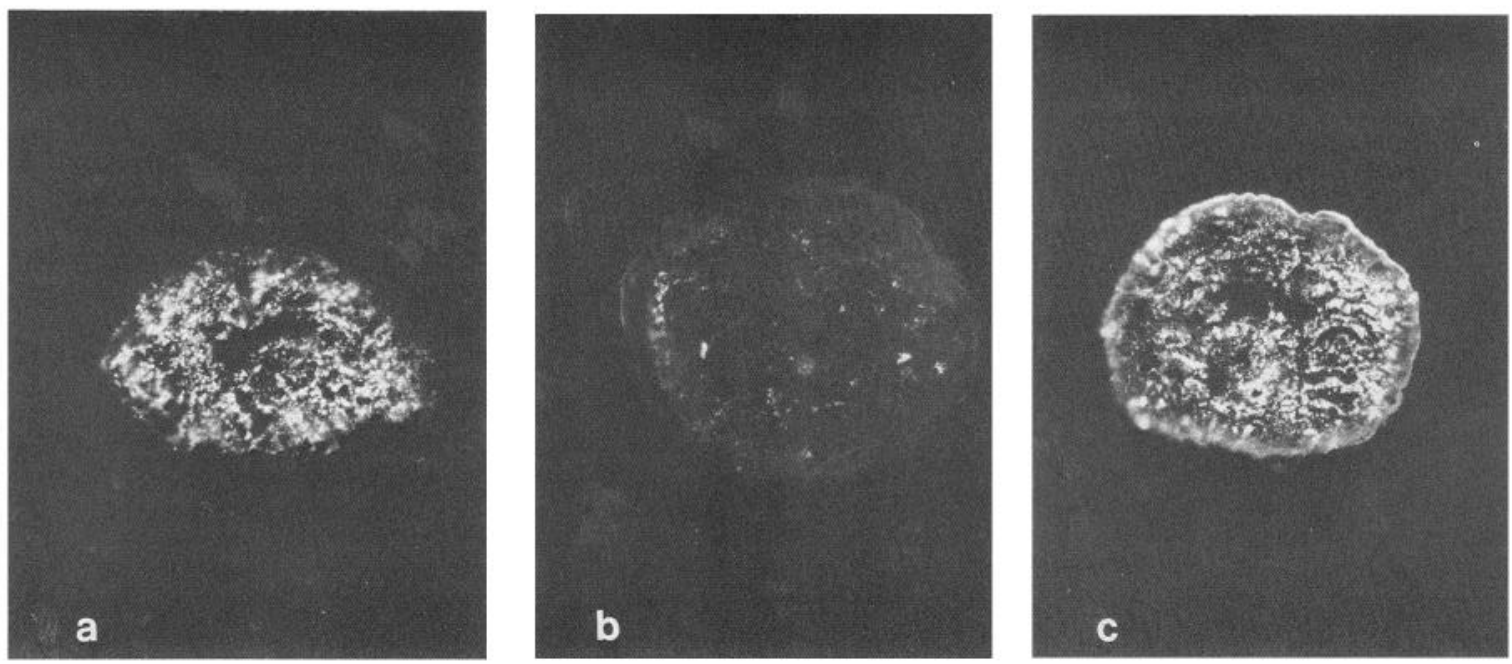

Figure 4. GC immunofluorescence in glutaraldehyde/osmium-fixed frozen sections of cervical sympathetic trunk. Sections were labeled with antibodies to GC. $a$, Transverse section through control cervical sympathetic trunk. Note discrete GC labeling throughout the section, except in the middle, where a black area indicates the position of a neuronal cell body. $b$, Transverse section through the distal stump of the cervical sympathetic trunk $9 \mathrm{~d}$ after nerve cut. The GC labeling is barely visible. $c$, Transverse section through the distal stump of the cervical sympathetic trunk 2 months after nerve crush. The regeneration of axons, visualized by neurofilament labeling in Figure 5, is accompanied by restoration of GC labeling. The black areas in the section indicate the position of neuronal cell bodies. 

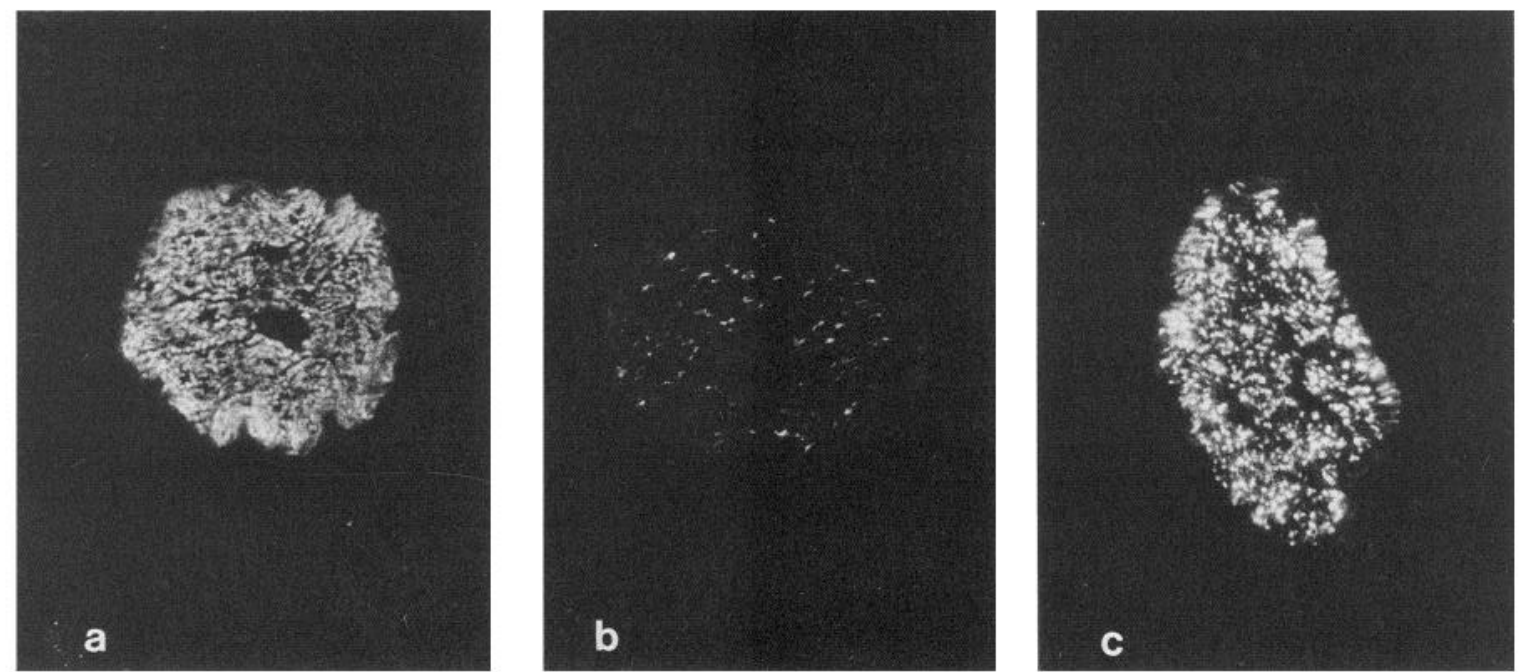

Figure 5. Neurofilament immunofluorescence in frozen sections of cervical sympathetic trunk. Sections were labeled with antibodies to neurofilament. $a$, Transverse section through control cervical sympathetic trunk. Note bright axonal labeling throughout the section. $b$, Transverse section through the distal stump of the cervical sympathetic trunk $9 \mathrm{~d}$ after nerve cut. The neurofilament labeling is very much diminished, but some intact axons, visualized by immunofluorescence, are still visible within the nerve. $c$, Transverse section through the distal stump of the cervical sympathetic trunk 2 months after nerve crush. Note that the neurofilament label in the stump is comparable to that seen in the control section (a), indicating that regrowth of axons has occurred.

in situ in rats $10 \mathrm{~d}$ of age or older (Jessen et al., 1985).

At intervals from $2 \mathrm{~d}$ to 2 months after crushing the left cervical sympathetic trunk, the distal stump was excised and the Schwann cells enzymatically dissociated and cytocentrifuged or air-dried onto a microscope slide. Immunolabeling of these cells with antibodies to GC and S-100, as in the sciatic nerve, enabled us to monitor quantitatively the change in the number of GC-positive Schwann cells in the stump following axonal degeneration and subsequent regeneration (Fig. 3). At $2 \mathrm{~d}$ following crush, $52.9 \pm 6.84 \%$ of Schwann cells in the distal stump were GC-positive, $26.8 \pm 4.71 \%$ were positive $4 \mathrm{~d}$ after injury, and $19.5 \pm 6.09 \%$ were positive after $6 \mathrm{~d}$. Thereafter, the percentage of GC-positive Schwann cells rose to $76.7 \pm 10.85 \%$ at 2 weeks following crush; at 3 weeks it had risen to $85.5 \pm 6.89 \%$, and at 2 months $93.5 \pm 2.78 \%$ of all Schwann cells were GCpositive. This figure was comparable to that found in the Schwann cells of the nerve on the unoperated side during the whole period of regeneration of the crushed nerve. These changes in GC expression could be confirmed qualitatively by using antibodies to visualize GC in cryostat sections of fixed nerves (Fig. 4). In normal nerves, GC labeling was apparent throughout the nerve, except in the area occupied by neuronal cell bodies (see below). No diminution in GC labeling was seen after crush on the contralateral side. Seven days after crush, distal stumps showed only very sparse GC immunolabeling, while at 2 months normal levels of labeling were again evident.

In other experiments, the sympathetic trunk was cut rather than crushed and stringent precautions taken to prevent reinnervation of the distal stump. It was found that the number of GC-positive Schwann cells fell to essentially the same levels as in the crushed nerves, i.e., $16.3 \pm 4.43 \%$ at $7 \mathrm{~d}$ postoperatively (Fig. 3). In separate experiments using air-dried cells, it was ascertained that the number of GC-positive Schwann cells did not change significantly over the period from $7 \mathrm{~d}$ to 2 months in the denervated distal stump, provided that reinnervation was prevented. For this purpose, GC expression was monitored as described above in the distal stump of cut nerves at $7 \mathrm{~d}, 4$ weeks, and 2 months after injury, 6 rats being killed for each time point. Taken together, these experiments on crushed and cut trunks showed that, in this nerve, as in the sciatic nerve, loss of axons leads to loss of GC expression from non-myelin-forming Schwann cells, while regeneration of axons into the distal stump is accompanied by re-expression of GC.

An explanation for the persistent presence of a small population of Schwann cells expressing GC in the distal stump of cut nerves, and in the stump $7 \mathrm{~d}$ after crush, can almost certainly be found in the observation that a considerable number of neurons lie scattered along the length of the trunk (Dyck and Hopkins, 1972). The axons originating from neurons distal to a cut or crush will remain unharmed and be able to support GC synthesis in the Schwann cells that surround them. A series of experiments using frozen sections and neurofilament antibodies to visualize axons confirmed the presence of these intrinsic axons, and also demonstrated the occurrence of effective axonal regeneration into the crushed stumps (Fig. 5). Control nerves showed strong neurofilament staining throughout the nerve, except in regions where neuronal cell bodies could be seen by phase-contrast microscopy. The antibodies to neurofilament did not label neuronal cell bodies in sections. In contrast, in frozen sections of the distal stump taken $7 \mathrm{~d}$ after crush or cut (when the number of Schwann cells expressing GC had fallen to basal levels, i.e., 15-20\%), neurofilament labeling was greatly reduced. It was clear, however, that following either type of operation, small, discrete areas of labeling could still be detected, indicating that some axons were still present in the stump. In parallel experiments on distal stumps from the sciatic nerve $7 \mathrm{~d}$ after cut or crush, no neurofilament labeling was detectable, while normal nerve showed extensive labeling of axons (results not shown). It seems clear that the axons remaining in the sympathetic trunk originate from the neuronal cell bodies intrinsic to the trunk. Four weeks after crush, normal levels of neurofilament labeling could again be seen. 


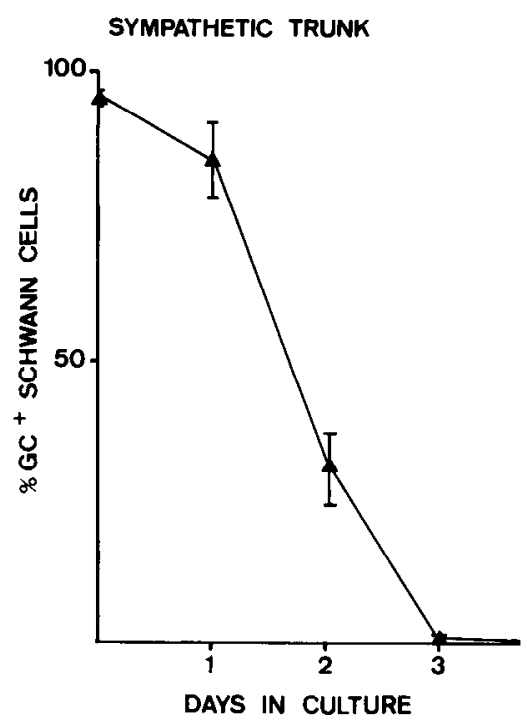

Figure 6. Disappearance of GC in S-100-positive Schwann cells in dissociated cell cultures from adult cervical sympathetic trunk. Cells were labeled with antibodies to $\mathrm{GC}$ and S-100 at different times in vitro, as described in Materials and Methods. Results at each time point were obtained from a minimum of 3 experiments, with a total of at least 1000 Schwann cells counted.

\section{GC expression in dissociated Schwann cell cultures from adult nerves}

GC expression was monitored over a period of several days in Schwann cell cultures derived from sympathetic trunks of adult rats. The object was 2-fold: to confirm in vitro that all mature non-myelin-forming Schwann cells lose GC when removed from axonal contact, and to test whether the extracellular matrix, in which the Schwann cell lies embedded in situ, exerts any influence on GC expression in adult non-myelin-forming Schwann cells.

Dissociated cell cultures from the cervical sympathetic trunks of $90-110 \mathrm{gm}$ rats were grown on poly-L-lysine-coated coverslips in medium containing either FCS or calf serum. In immunohistochemical experiments, $95 \%$ of Schwann cells, identified by the presence of intracellular S-100 protein (Brockes et al., 1979; Mirsky and Jessen, 1984), expressed GC at $3 \mathrm{hr}$ in vitro, 50\% were GC-positive at $2 \mathrm{~d}$ in vitro, and, at $5 \mathrm{~d}$ in vitro, fewer than $1 \%$ were GC-positive (Fig. 6 and Table 1). In cultures from neonatal rats, some Schwann cells in which GC is no longer detectable can be induced to express immunohistochemically detectable levels of GC in the presence of high levels of cyclic AMP or its derivatives in the presence of calf serum (Sobue and Pleasure, 1984), but not in the presence of FCS. Therefore, the effect of calf serum on the disappearance of GC was tested. The rate of disappearance of GC from Schwann cells derived from unmyelinated fibers was the same in calf serum as in FCS. The rate of decline of GC from the adult non-myelin-forming cells in these cultures was similar to that seen in myelin-forming Schwann cells derived from either 5-d-old (Mirsky et al., 1980) or adult (Jessen et al., 1985) rats. Thus, in both developing (10d-old) (Jessen et al., 1985) and adult rats, non-myelin-forming Schwann cells that are GC-positive in situ lose GC when they are cultured in vitro. When the Schwann cells maintained in situ in the distal stump are compared with those maintained without axonal contact in tissue culture, the decline in the percentage of

\begin{tabular}{|c|c|c|c|c|}
\hline \multirow[b]{2}{*}{$\begin{array}{l}\text { Days in } \\
\text { culture }\end{array}$} & \multicolumn{4}{|c|}{$\%$ S-100 Schwann cells expressing GC on } \\
\hline & $\begin{array}{l}\text { Poly-L- } \\
\text { lysine }\end{array}$ & $\begin{array}{l}\text { Poly-L- } \\
\text { lysine plus } \\
\text { laminin }\end{array}$ & $\begin{array}{l}\text { Poly-L- } \\
\text { lysine plus } \\
\text { collagen }\end{array}$ & $\begin{array}{l}\text { Poly-L- } \\
\text { lysine plus } \\
\text { ECM }\end{array}$ \\
\hline 1 & $84.4 \pm 6.82$ & $86.9 \pm 2.15$ & $88.1 \pm 2.30$ & $88.8 \pm 2.28$ \\
\hline 2 & $31.6 \pm 6.49$ & $26.1 \pm 7.79$ & $26.7 \pm 2.65$ & $23.1 \pm 8.80$ \\
\hline 3 & $1.6 \pm 0.30$ & $1.0 \pm 0.40$ & $6.38 \pm 5.37$ & $0.6 \pm 0.54$ \\
\hline 4 & $0.1 \pm 0.08$ & $0.1 \pm 0.07$ & $0 \pm 0$ & $0.42 \pm 0.52$ \\
\hline
\end{tabular}

GC-positive Schwann cells occurs over a slightly longer time period in situ than in culture.

To test the effects of basal lamina components on the expression of GC by Schwann cells in culture, dissociated cells from adult rat cervical sympathetic trunk were maintained on 3 different substrates. A comparison was made of the rates of disappearance of GC from the Schwann cells in these cultures when the cells were plated onto poly-L-lysine, poly-L-lysine plus laminin, rat tail collagen, and extracellular matrix from bovine endothelial cells. When the 4 substrates were compared, no significant difference was found in the percentage of GC-positive cells in the culture at days 1-4 in vitro (Table 1). Both laminin and the extracellular matrix appeared to stimulate Schwann cell division.

\section{Discussion}

There is now good evidence that contact with axons is important in certain early events in Schwann cell development, such as Schwann cell proliferation (Salzer and Bunge, 1980; De Vries et al., 1982; Ratner et al., 1985, 1986; Sobue and Pleasure, 1985) and basement membrane formation (Webster et al., 1973; Bunge et al., 1980, 1986). Later in development, axonal contact is also crucial for myelin synthesis by those Schwann cells that associate with the larger-diameter axons (Aguayo et al., 1976; Weinberg and Spencer, 1976; Mirsky et al., 1980). In the present paper we show that axons also play an essential role in inducing and maintaining the terminal differentiation of non-myelin-forming Schwann cells.

In situ GC disappears from the surface of non-myelin-forming Schwann cells when they are removed from axonal contact through axonal degeneration. When axonal contact is restored by regeneration of axons after nerve crush, $\mathrm{GC}$ reappears on non-myelin-forming cells as they establish a normal pattern of interaction with axons. In ccll culturc, single non-myclin-forming Schwann cells promptly lose detectable levels of surface GC even when the cells are derived from mature nerves in which $\mathrm{GC}$ expression has been established for weeks. The time course of this loss is not affected by contact with the extracellular matrix, another potential inducer of cellular differentiation. It seems clear, therefore, that the presence of axons is essential for nonmyelin-forming Schwann cells to maintain normal levels of this glycolipid in their plasma membrane. Thus, axonal control of Schwann cell membrane biosynthesis is not restricted to the formation and maintenance of myelin.

It is evident that the in situ disappearance of GC from nerves undergoing degeneration is reversible. Provided that axons are allowed to regenerate after crush injury, the restoration of GC 
expression in both the sciatic nerve and sympathetic trunk is complete, although this recovery takes a longer time in the sciatic nerve. During normal development, this nerve also lags behind the trunk in the attainment of full GC expression (Jessen et al., 1985), presumably because of the slow development of the non-myelin-forming Schwann cells (Peters and Muir, 1959; Diner, 1965; Friede and Samorajski, 1968; Aguayo et al., 1972, 1973).

While the time course of GC disappearance from myelinforming and non-myelin-forming cells is similar in culture, GC is, in situ, lost much more slowly from the myelin-forming cells. This slow decline in the number of GC-positive cells in situ almost certainly reflects the fact that, in this situation, large amounts of myelin debris are being ingested by Schwann cells. Since myelin debris is washed away from Schwann cells in dissociated cell culture the rapid disappearance of $G C$ and $P_{0}$ from Schwann cells in culture reflects more closely the rate at which Schwann cells stop synthesizing these molecules in response to loss of axonal contact.

The molecular mechanisms by which axons influence Schwann cells, enabling them to assemble basement membrane and express the myelin-related proteins or GC are unknown. There is biochemical evidence that in cut nerves GC synthesis falls to low levels, while the synthesis of glucocerebrosides is elevated, suggesting that the levels of galactosyl and glucosyl transferase are reciprocally affected by axonal contact (Poduslo, 1986). It is likely that the axonal signal that controls GC synthesis in both unmyelinated and myelinated fibers is similar. Experiments on GC expression in dissociated Schwann cells derived both from mixed nerves (Sobue and Pleasure, 1984) and from the cervical sympathetic trunk (Jessen et al., 1985) suggest that this signal may be related to elevated levels of cyclic AMP in the Schwann cells. It is possible, therefore, that the signal for GC biosynthesis, which can be provided by both unmyelinated and myelinated axons, is distinct from the signal that induces high levels of expression of the myelin proteins and leads to myelination of the larger axons.

In addition to the appearance of myelin-specific molecules and GC and basement membrane formation, several other steps in Schwann cell differentiation have now been defined in molecular terms. During development, at least 3 molecules appear in the plasma membrane of non-myelin-forming cells with a time course broadly similar to that of GC. They are the 140 kDa protein Ran-2 (Mirsky and Jessen, 1984) and 2 glycolipids defined by the monoclonal antibodies 08 and 09 (Eccleston et al., 1987). Ran-2 does not appear on myelin-forming cells, while both of the glycolipids are, like GC, also expressed by myelinforming cells. In contrast to these molecules, the $130 \mathrm{kDa}$ surface protein A5E3 (Mirsky et al., 1985), L1, and N-CAM (Nieke and Schachner, 1985) are present on Schwann cells prior to their differentiation into myelin- or non-myelin-forming cells, but are sclectivcly down-regulated in cells that have been induced to myelinate (Jessen and Mirsky, 1984; Daniloff et al., 1986; Mirsky et al., 1986; Jessen et al., 1987). Furthermore, nonmyelin-forming cells, but not myelin-forming ones, acquire glial fibrillary acidic protein (GFAP)-containing intermediate filaments (Yen and Fields, 1981; Jessen and Mirsky, 1984, 1985; Jessen et al., 1984). The availability of molecular markers of Schwann cell differentiation now makes it possible to analyze further the extent to which peripheral glia depend on neuronal signals for the attainment and maintenance of full differentiation.

\section{References}

Aguayo, A. J., J. B. Martin, and G. M. Bray (1972) Effects of nerve growth factor antiserum on peripheral unmyelinated nerve fibers. Acta Neuropathol. (Berl.) 20: 288-298.

Aguayo, A. J., L. C. Terry, and G. M. Bray (1973) Spontaneous loss of axons in sympathetic unmyelinated fibers of the rat during development. Brain Res. 54: 360-364.

Aguayo, A. J., L. Charron, and G. M. Bray (1976) Potential of Schwann cells from unmyelinated nerves to produce myelin: A quantitative ultrastructural and autoradiographic study. J. Neurocytol. 5: 565573.

Anderton, B. H., D. Breinburg, M. Downs, P. J. Green, B. E. Tomlinson, J. Ulrich, and J. N. Wood (1984) Monoclonal antibodies show that neurofibrillary tangles and neurofilaments share antigenic determinants. Nature 298: 84-86.

Brockes, J. P., K. L. Fields, and M. C. Raff (1979) Studies on cultured rat Schwann cells. I. Establishment of purified populations from cultures of peripheral nerve. Brain Res. 165: 105-118.

Bunge, M., A. Williams, P. Wood, J. Uitto, and J. Jeffrey (1980) Comparison of nerve cell and nerve cell plus Schwann cell cultures, with particular emphasis on basal lamina and collagen formation. J. Cell Biol. 84: 184-202.

Bunge, R. P., M. B. Bunge, and C. F. Eldridge (1986) Linkage between axonal ensheathment and basal lamina production by Schwann cells. Annu. Rev. Neurosci. 9: 305-328.

Daniloff, J. K., G. Levi, M. Grumet, F. Rieger, and G. M. Edelman (1986) Altered expression of neuronal cell adhesion molecules induced by nerve injury and repair. J. Cell Biol. 103: 929-945.

De Vries, G. H., J. L. Salzer, and R. P. Bunge (1982) Axolemmaenriched fractions isolated from PNS and CNS are mitogenic for cultured Schwann cells. Dev. Brain Res. 3: 295-299.

Diner, O. (1965) Les cellules de Schwann en mitose et leurs rapports avec les axones au cours du developpement du nerf sciatique chez le rat. C. R. Acad. Sci. [D] (Paris) 261: 1731-1734.

Dyck, P. J., and A. P. Hopkins (1972) Electron microscopic observations on degeneration and regeneration of unmyelinated nerves. Brain 95: 223-234.

Eccleston, P. A., R. Mirsky, K. R. Jessen, I. Sommer, and M. Schachner (1987) Postnatal development of rat peripheral nerves: An immunohistochemical study of membrane lipids common to non-myelin forming Schwann cells, myelin forming Schwann cells and oligodendrocytes. Dev. Brain Res. (in press).

Friede, R. L., and T. Samorajski (1968) Myelin formation in the sciatic nerve of the rat. J. Neuropathol. Exp. Neurol. 27: 546-569.

Hirsch, J. G., and M. E. Fcdorko (1968) Ultrastructure of human leukocytes after simultaneous fixation with glutaraldehyde and osmium tetroxide and "post fixation" in uranyl. J. Cell Biol. 38: 615627.

Jessen, K. R., and R. Mirsky (1984) Non-myelin-forming Schwann cells coexpress surface proteins and intermediate filaments not found in myelin forming cells: A study of Ran-2, A5E3 antigen and glial fibrillary acidic protein. J. Neurocytol. 13: 923-934.

Jessen, K. R., and R. Mirsky (1985) Glial fibrillary acidic polypeptides in peripheral glia: Molecular weight, heterogeneity and distribution. J. Neuroimmunol. 8: 377-393.

Jessen, K. R., R. Thorpe, and R. Mirsky (1984) Molecular identity, distribution and heterogeneity of glial fibrillary acidic protein: An immunoblotting and immunohistochemical study of Schwann cells, satcllite cells, enteric glia and astrocytes. J. Ncurocytol. 13: 187-200.

Jessen, K. R., L. Morgan, M. Brammer, and R. Mirsky (1985) Galactocerebroside is expressed by non-myelin forming Schwann cells in situ. J. Cell Biol. 101: 1135-1143.

Jessen, K. R., R. Mirsky, and L. Morgan (1987) Myelinated but not unmyelinated axons reversibly down-regulate N-CAM in Schwann cells. J. Neurocytol. (in press).

Mirsky, R., and K. R. Jessen (1984) A cell surface protein of astrocytes, Ran-2, distinguishes non-myelin forming Schwann cells from myelin forming Schwann cells. Dev. Neurosci. 6: 304-316.

Mirsky, R., J. Winter, E. R. Abney, R. M. Pruss, J. Gavrilovic, and M. C. Raff (1980) Myelin-specific proteins and glycolipids in rat Schwann cells and oligodendrocytes in culture. J. Cell Biol. 84: 483-494.

Mirsky, R., J. Gavrilovic, P. Bannerman, J. Winter, and K. R. Jessen (1985) Charactcrization of a plasma membrane protein present in non-myelin forming PNS and CNS glia, a subpopulation of PNS 
neurons, perineurial cells and smooth muscle in adult rats. Cell Tissue Res. 240: 723-733.

Mirsky, R., K. R. Jessen, M. Schachner, and C. Goridis (1986) Distribution of the cell adhesion molecules N-CAM and $L 1$ on peripheral neurons and glia in adult rats. J. Neurocytol. 15: 799-815.

Nieke, J., and M. Schachner (1985) Expression of the neural cell adhesion molecules $\mathrm{Ll}$ and N-CAM and their common carbohydrate epitope L2-HNK-1 during development and after transection of adult mouse sciatic nerve. Differentiation 30: 141-151.

Peters, A., and A. R. Muir (1959) The relationship between axons and Schwann cells during development of peripheral nerves in the rat. $Q$. J. Exp. Physiol. 44: 117-130.

Peyronnard, J. M., A. J. Aguayo, and G. M. Bray (1973) Schwann cell internuclear distances in normal and regenerating unmyelinated nerve fibres. Arch. Neurol. 29: 56-59.

Poduslo, J. F. (1986) Control of myelin glycoconjugate expression by Schwann cells. Muscle Nerve (Suppl. 5) 9: 60.

Poduslo, J. F., P. J. Dyck, and C. T. Berg (1985) Regulation of myelination: Schwann cell transition from a myelin-maintaining state to a quiescent state after permanent nerve transection. J. Neurochem. 44: 388-400.

Ranscht, B., P. A. Clapshaw, J. Price, M. Noble, and W. Seifert (1982) Development of oligodendrocytes and Schwann cells studied with a monoclonal antibody against galactocerebroside. Proc. Natl. Acad. Sci. USA 79: 2709-2713.

Ratner, N., A. Elhein, M. B. Bunge, and L. Glaser (1985) A neuronal heparan sulfate proteoglycan is required for dorsal root ganglion neuron stimulation of Schwann cell proliferation. J. Cell Biol. 101: 744 754.

Ratner, N., A. Elbein, M. B. Bunge, S. Porter, R. P. Bunge, and L. Glaser (1986) Specific asparagine-linked oligosaccharides are not required for certain neuron-neuron and neuron-Schwann cell interactions. J. Cell Biol. 103: 159-170.
Salzer, J. L., and R. P. Bunge (1980) Studies of Schwann cell proliferation I. An analysis in tissue culture of proliferation during development, Wallerian degeneration and direct injury. J. Cell Biol. 84: 739-752.

Schlaepfer, W. W., and F. K. Myers (1973) Relationship of myelin internode elongation and growth in the rat sural nerve. J. Comp. Neurol. 147: 255-266.

Sobue, G., and D. Pleasure (1984) Schwann cell galactocerebroside induced by derivatives of adenosine $3^{\prime}, 5^{\prime}$-monophosphate. Science 224: 72-74.

Sobue, G., and D. Pleasure (1985) Adhesion of axolemmal fragments to Schwann cells: A signal- and target-specific process closely linked to axolemmal induction of Schwann cell mitosis. J. Neurosci. 5: 379387.

Webster, H. de F. (1971) The geometry of peripheral myelin sheaths during their formation and growth in rat sciatic nerves. J. Cell Biol. 48: $348-367$

Webster, H. de F., J. R. Martin, and M. F. O'Connell (1973) The relationships between interphase Schwann cells and axons before myelination: A quantitative electron microscopic study. Dev. Biol. 32: $401-416$

Weinberg, H., and P. S. Spencer (1976) Studies on the control of myelinogenesis II. Evidence for neuronal regulation of myelination. Brain Res. 113: 363-378.

Winter, J., R. Mirsky, and M. Kadlubowski (1982) An immunocytochemical study of the appearance of $\mathrm{P}_{2}$ in developing rat peripheral nerve: Comparison with other myelin components. J. Neurocytol. 11 . 351-362.

Wood, J., and B. Anderton (1981) Monoclonal antibodies to mammalian neurofilaments. Biosci. Rep. 1: 263-268.

Yen, S. H., and K. L. Fields (1981) Antibodies to neurofilament, glial filament, and fibroblast intermediate filament proteins bind to different cell types in the nervous system. J. Cell Biol. 88: 115-126. 